Document downloaded from:

http://hdl.handle.net/10251/64907

This paper must be cited as:

Antolinos Turpín, CM.; Morales Román, RM.; Ródenas Rochina, J.; Gómez Ribelles, JL.; Gómez-Tejedor, JA. (2015). Macroporous thin membranes for cell transplant in regenerative medicine. Biomaterials. 67:254-263. doi:10.1016/j.biomaterials.2015.07.032.

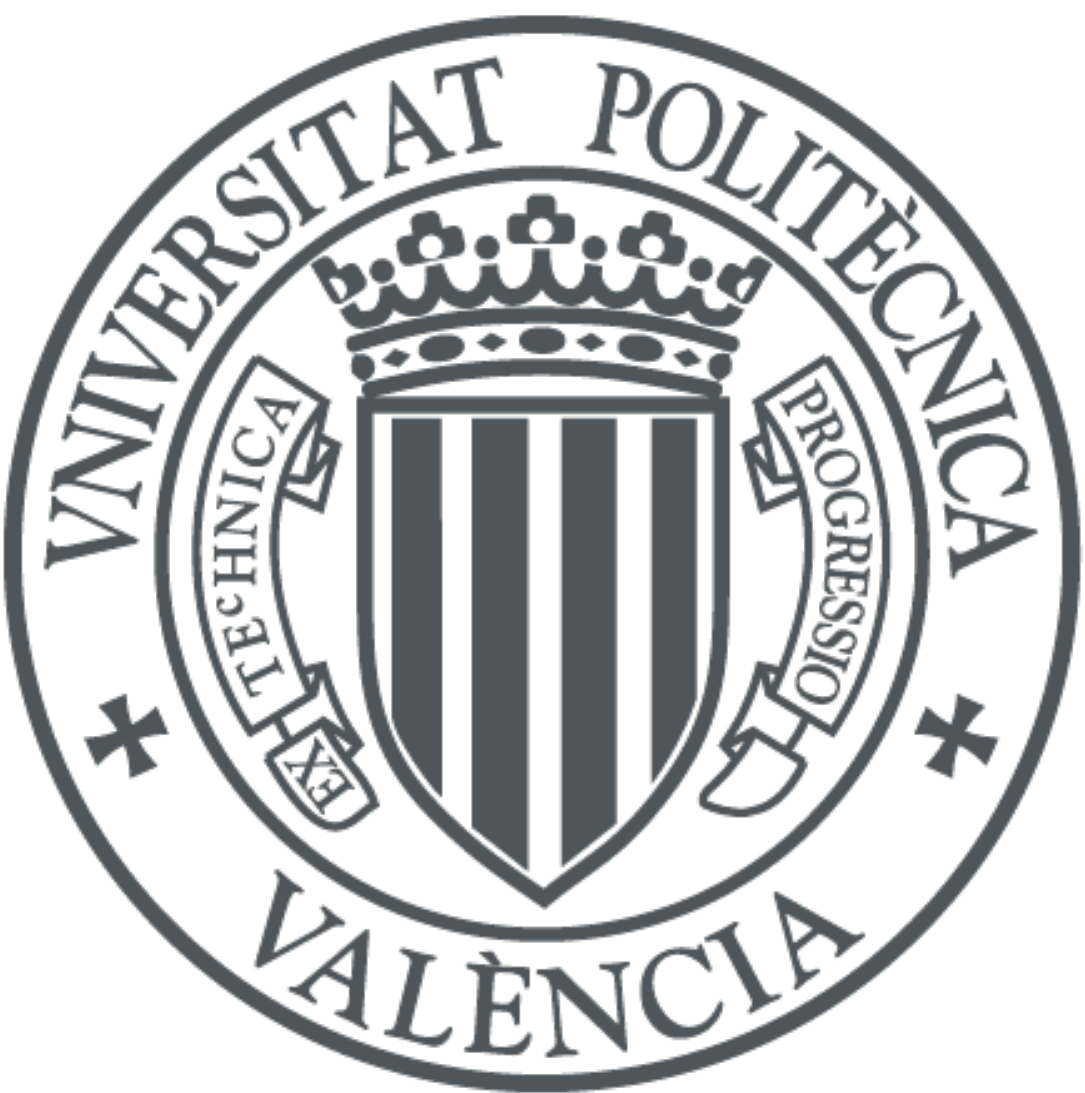

The final publication is available at

http://dx.doi.org/10.1016/j.biomaterials.2015.07.032

Copyright Elsevier

Additional Information 


\section{Macroporous thin membranes for cell transplant in}

\section{regenerative medicine}

C.M. Antolinos-Turpín ${ }^{1}$, R.M. Morales Román ${ }^{1}$, J. Rodenas-Rochina ${ }^{1}$, J. L. Gómez Ribelles $^{1,2}$, J.A. Gómez-Tejedor ${ }^{1, *}$

${ }^{1}$ Centre for Biomaterials and Tissue Engineering, CBIT, Universitat Politècnica de València, Camino de Vera s/n, 46022 Valencia, Spain.

${ }^{2}$ Networking Research Center on Bioengineering, Biomaterials and Nanomedicine (CIBER-BBN), Valencia, Spain

*Corresponding author. E-mail: jogomez@fis.upv.es; Tel.: +34 963877007; fax: +34 963877276.

Biomaterials 67 (2015) 254-263

http://dx.doi.org/10.1016/j.biomaterials.2015.07.032 


\begin{abstract}
The aim of this paper is to present a method to produce macroporous thin membranes made of poly (ethyl acrylate-co-hydroxyethyl acrylate) copolymer network with varying cross-linking density for cell transplantation and prosthesis fabrication. The manufacture process is based on template techniques and anisotropic pore collapse. Pore collapse was produced by swelling the membrane in acetone and subsequently drying and changing the solvent by water to produce 100 microns thick porous membranes. These very thin membranes are porous enough to hold cells to be transplanted to the organism or to be colonized by ingrowth from neighboring tissues in the organism, and they present sufficient tearing stress to be sutured with surgical thread. The obtained pore morphology was observed by Scanning Electron Microscope, and confocal laser microscopy. Mechanical properties were characterized by stress-strain experiments in tension and tearing strength measurements. Morphology and mechanical properties were related to the different initial thickness of the scaffold and the cross-linking density of the polymer network. Seeding efficiency and proliferation of mesenchymal stem cells inside the pore structure were determined at 2 hours, 1, 7, 14 and 21 days from seeding.
\end{abstract}

Keywords: Macroporous thin membrane; poly (ethyl acrylate-co-hydroxyethyl acrylate) copolymer; mesenchymal stem cells; tearing stress.

\title{
INTRODUCTION
}

Biostable cell carriers can find application in the biointegration of prosthetic implants and as natural source of growth factors in different regenerative therapies. In some of these applications flexible and quite thin macroporous membranes, with a thickness around $100 \mu \mathrm{m}$, are required. This is the case of the anchorage ring of cornea prosthesis, for which a thin biointegrable biostable material is required [1-9]. In other cases a patch of a biostable material for cell carrier can be pressed on the damaged tissue to induce a paracrinic effect by a continuous growth factor delivery, this could find application in wound healing, and cornea or skin regeneration [10-17]. Pore architecture of these scaffolds must be quite particular to fit simultaneously requirements of high porosity (as large as possible), pore interconnectivity, and 
pore size adequate for cell invasion, small thickness and mechanical resistance. Some of these requirements seem quite contradictory with each other. Mechanical strength is a critical scaffold requirement. If the scaffold cannot provide a mechanical modulus in the range of native tissues, then any nascent tissue formation will probably fail [18]. Conventional techniques to produce scaffolds for tissue engineering applications such as template or particle leaching techniques [19-25] with pore sizes in the order of several tens of microns would yield scaffolds that would disaggregate when cut to produce membranes with thicknesses in the order of magnitude of pore sizes. Freeze extraction or freeze gelation techniques [24, 26-32] yield materials with very high porosity what makes them very weak in the form of thin films. Electrospinning would allow producing very thin and quite resistant mats but the spaces among nanofibers do not allow cell invasion [33-37].

In this work we propose a new method based on anisotropic pore collapse to produce 100 microns thick macroporous membranes with mechanical properties adequate for the applications mentioned above. We have checked that their porosity and pore sizes allow cell invasion, by seeding mesenchymal stem cells on one side of the membrane. In any case, more emphasis should be done in some properties, depending on the application. For instance, for the anchoring ring of a corneal prosthesis, the scaffold should resist the surgical suture, and thus a high resistance to tearing is required. For cell carriers, the mechanical properties are lest important, and it is more important the size and inter-connection between pores. Because of this reason, in this paper we do not propose a solely material as an ideal material, instead of that we have proposed a novel method to obtain material in an appropriate range of mechanical properties, porosity and pore interconnections. These membranes are made of poly(ethyl acrylate-cohydroxyethyl acrylate) copolymer networks, these materials have been proposed previously as cell culture supports or to produce the anchoring ring of a cornea prosthesis [38-40]. The relationship between cross-linking density of the network and microstructure and mechanical properties of the membranes is studied. Cell seeding efficiency and mesenchymal stem cells viability and proliferation is also analyzed. 


\section{MATERIALS AND METHODS}

\section{Macroporous membranes preparation}

Macroporous scaffolds were prepared with a template technique [20, 21, 41]. Template was formed by sintering poly (methyl methacrylate) PMMA (Lucite International Colacryl DP 300, USA) microspheres, with diameter ranging from 90 to $120 \mu \mathrm{m}$. The porogen microspheres were placed into a metal mold and subjected to successive compressions at $150^{\circ} \mathrm{C}$ in the hot press to obtain the template in the form of a sheet with a suitable interconnection of the PMMA particles. Copolymer network was produced by in situ polymerization of mixtures of ethyl acrylate, EA 99\% pure (Scharlau, Spain), with hydroxyethyl acrylate, HEA 96\% pure (Aldrich, Spain), in the proportion 90/10 (w/w)\% respectively, using ethylene glycol dimethacrylate, EGDMA 99\% pure (Aldrich, Spain), as cross-linking agent in the proportion of 1, 3 and $5 \mathrm{wt} \%$, and $0,5 \mathrm{wt} \%$ of benzoin $98 \%$ pure (Scharlau, Spain) as photoinitiator. Monomers mixture was injected into de voids of the templates and polymerized at room temperature under UV light and then post cured at $90^{\circ} \mathrm{C}$ for 24 hours.

The obtained plates were washed for 24 hours to remove the porogen using acetone as solvent and then changing the solvent by water to produce porous plates $1500 \mu \mathrm{m}$ thick with an interconnected 3D structure of spherical pores. The original plates were cut out with a rotation microtome MICROM HM350 SV to obtain membranes with different thickness: $180 \mu \mathrm{m}$, $300 \mu \mathrm{m}$ or $500 \mu \mathrm{m}$. The pore collapse was produced by swelling the scaffold $(180 \mu \mathrm{m}, 300 \mu \mathrm{m}$, $500 \mu \mathrm{m}$ and $1500 \mu \mathrm{m}$ thick) in acetone and subsequently drying and suddenly changing the solvent by water when the sheets reach $100 \mu \mathrm{m}$ thick. The pore collapse was stopped when the samples reached the same thickness than a $100 \mu \mathrm{m}$ feeler gauge, which was evaluated by visual comparison. Afterwards, the thickness was measured with a caliper, checking that all samples were in the $10 \%$ interval error. Samples will be designed by COP-X-R being $\mathrm{X}$ the EGDMA content and $\mathrm{R}$ the original thickness to final thickness ratio $(\mathrm{R}=1.8,3,5$ or 15$)$.

\section{$\underline{\text { Microestructural characterization of macroporous membranes }}$}


Microstructure of the surface and cross-section of dry macroporous membranes was examined by scanning electron microscopy, SEM, using a JEOL JSM 6300 microscope (Japan) at an accelerating voltage of $10 \mathrm{kV}$. The samples were coated with gold by sputtering for 90 seconds (JFC 1100, JEOL, Japan) to make conductive the surface of the samples. Depth and interconnection of pores in macroporous membranes was observed by scanning confocal laser microscopy, using a Nikon C1 microscope (Japan).

The porosity of the original scaffold, $\phi$, was determined by geometric and volumetric measurements, according to the equation [42]:

$$
\phi=1-\frac{m / \rho}{t \cdot w l},
$$

where $m$ is the scaffold mass, $\rho$ is the polymer density and $t, w$ and $l$ are the thickness, weight and length of the scaffold respectively. 


\section{Mechanical properties of macroporous membranes}

The mechanical properties of the macroporous membranes were analyzed by tensile stress-strain experiments and testing the resistance to tearing [43, 44]. All results were the average of 5 specimens, and are expressed as mean \pm standard deviation.

Tearing Strength. Experiment was performed in a Microtest Universal testing machine, SCM 3000095 (Spain) with a $15 \mathrm{~N}$ force transducer in tensile mode. The dimensions of the macroporous membranes tested were $30 \times 10 \times 0.1 \mathrm{~mm}^{3}$. Two holes were created at $0.5 \mathrm{~mm}$ from each end of the membranes using a surgical needle. Two copper threads of $0.1 \mathrm{~mm}$ of diameter were passed through the holes and a tensile mode strain-rate program at a speed of $10 \mathrm{~mm} / \mathrm{min}$ was performed until sample breaking. The strength during crack propagation until failure was measured (see Fig. S2).

Tensile Experiments. Stress-strain experiments were performed in a Seiko EXSTAR TMA/SS6000 thermo-mechanical analyzer (Japan). The macroporous membranes with dimensions of $9 \times 5 \times 0.1 \mathrm{~mm}^{3}$ were clamped at both ends with metal jaws and tensile experiment was performed at a force rate of $20 \mathrm{mN} / \mathrm{min}$ up to a maximum force of $1000 \mathrm{mN}$. From the slope in the initial linear region, the apparent elastic modulus was calculated.

\section{Cell collecting and sub culturing}

Seeding efficiency and cell viability and proliferation was assessed in the membranes described previously with porcine bone marrow mesenchymal stem cells. Cells were collected from femora bone marrow obtained from a 4-month-old porcine specimen. Under laminar flow hood femora head was removed and gelatinous bone marrow was collected from medullary cavity. Bone marrow femora was resuspended and homogenized in DMEM GlutamaX supplemented with $10 \%$ FBS and $1 \%$ penicillin/streptomycin. Cell suspension was centrifuged at $650 \mathrm{~g}$ for 5 minutes and supernatant discarded. Previous step was repeated after cell resuspension once more. Pellet was resuspended in culture medium and filtered using a $40 \mu \mathrm{m}$ nylon filter. Cells were seeded at $4 \times 10^{5}$ cells $/ \mathrm{cm}^{2}$ in a $775 \mathrm{~cm}^{2}$ culture flask and expanded in monolayer culture 
until passage 1 with Dulbecco's Modified Eagle's Medium, DMEM GlutamaX (Gibco, UK), supplemented with $10 \%$ of fetal bovine serum, FBS (Gibco, UK), $2 \%$ penicillin/streptomycin (Gibco, UK), 5ng/ml human recombinant fibroblast growth factor-2 (FGF-2) (Eurobio) and $125 \mu \mathrm{g} / \mathrm{ml}$ amphotericin B (Sigma Aldrich, Spain). Cells were concentrated at $2 \times 10^{6}$ cells $/ \mathrm{ml}$ and cryopreserved in freezing medium (90\% FBS with $10 \%$ dimethyl sulfoxide). Prior to cell seeding cells were unfrozen at $37^{\circ} \mathrm{C}$ in a water bath for 1 minute and seeded at $3 \times 10^{3}$ cells $/ \mathrm{cm}^{2}$ in a T75 $\mathrm{cm}^{2}$ culture and expanded until passage 2 with DMEM GlutaMAX, supplemented with $10 \%$ FBS, $2 \%$ penicillin / streptomycin, and $5 \mathrm{ng} / \mathrm{ml}$ human recombinant fibroblast growth factor-2 (FGF-2) (Eurobio).

\section{Cell cultured on macroporous membranes}

The macroporous membranes were cut in circular discs of $5 \mathrm{~mm}$ in diameter. The samples were sterilized with $25 \mathrm{kGy}$ gamma radiation (Aragogamma S.A., Spain) prior to cell culture. In the seeding efficiency study samples were washed with a phosphate buffered saline solution, PBS at $7.4 \mathrm{pH}$, and conditioned overnight in DMEM supplemented with $1 \%$ penicillin/streptomycin in the incubator. Before cell seeding the samples were incubated 1 hour with $20 \mu \mathrm{g} / \mathrm{ml}$ of fibronectin in order to allow for protein adsorption onto the scaffolds. Samples for long-term proliferation study were washed in Dulbecco's phosphate buffered saline, DPBS, and conditioned overnight in DMEM with $1 \%$ penicillin/streptomycin and 10\% FBS in order to allow for protein adsorption. After conditioning excess medium was aspirated with a pipette and membranes were placed into agar coated 96 well culture plates.

Cells from passage 2 were detached and suspended in free serum DMEM GlutamaX enriched supplemented with $1 \%$ penicillin/streptomycin to obtain a final concentration of approximately $5 \times 10^{4}$ cells $/ \mathrm{ml}$. In the short term seeding study, $100 \mu 1 /$ sample of cell suspension was pipetted on each sample and placed in the incubator at $37^{\circ} \mathrm{C}$ in a $5 \% \mathrm{CO}_{2}$ atmosphere, 12 hours after cell seeding culture medium was changed by DMEM GlutamaX enriched with $10 \%$ FBS, $1 \%$ 
penicillin/streptomycin and $5 \mathrm{ng} / \mathrm{mL}$ FGF-2. The samples were cultured at $37^{\circ} \mathrm{C}$ in normoxic conditions. Culture medium was changed four times per week and samples were collected at 2 hours for all porous membranes of different amounts of cross-linking agent. In addition membranes with 3\% EGDMA (COP-3-R series) were cultured for 1, 7, 14 and 21 days.

\section{Cell proliferation assay}

Cell proliferation was determined by quantifying the total amount of DNA in the samples using P7589 Quant-iT Picogreen dsDNA assay kit (Invitrogen). Four samples for each type of membrane were removed at $2 \mathrm{~h}, 1,7,14$ and 21 days. Samples were washed with DPBS and stored in a microtube at $-80{ }^{\circ} \mathrm{C}$. Samples were digested with proteinase $\mathrm{K}$ to release the DNA and measured it with Quant-iT ${ }^{\text {TM }}$ PicoGreen ${ }^{\circledR}$ dsDNA Reagent and Kit as in previous works $[45,46]$.

$\underline{\text { Immunofluorescence assay }}$

Detection of focal adhesions was performed by immunofluorescence of cell markers with fluorescence optical microscopy. For vinculin immunostaining after 2 hours culture, the samples were fixed 1 hour at $2-8^{\circ} \mathrm{C}$ with formalin $10 \%$ and stored in DPBS with sodium azide $0.5 \%$. Immunostaining was carried out following standard protocols. Staining was performed on one side of the samples. Mouse anti-vinculin (1:50, Millipore) incubated overnight at $4^{\circ} \mathrm{C}$ and $\mathrm{Cy}-3$ antimouse (1:200, Invitrogen) as a secondary antibody with Bodipy phallacidin (1:200, Invitrogen) were used for vinculin. Cytoskeleton morphology was studied at day 1, 7, 14 and 21. Cytoskeleton was stained on permeabilized samples incubating with Bodipy phallacidin (1:200, Invitrogen) for 2 hours. Finally the samples were mounted with Fluorsave Vectashield mounting medium with DAPI (Atom).

\section{Tridimensional cell distribution and quantification}

Cell nucleus position was determined by immunofluorescence of DAPI nuclear staining with a confocal fluorescence microscope mounted on an inverted Zeiss microscope and software Nis- 
elements (Nikon). Samples were permeabilized with Triton X-100 0.1\% 10 minutes previous to mount the samples with Fluorsave Vectashield mounting medium with DAPI (Atom) to stain the nucleus. Pictures were taken from 4 randomly selected sample's regions at different depths from the surface, separated $1.5 \mu \mathrm{m}$ from each other until fluorescence was not detected. Pictures were divided in 4 sections to quantify the nuclei distribution. Nuclei detected in stacks $0,15,30$ and $40 \mu \mathrm{m}$ depth from the surface of the sample were counted. The fraction of cells hosted at each depth was represented as percentage of total number of cells counted in the four layers.

$\underline{\text { Statistical analysis }}$

Statistical analysis was done by two-way ANOVA using GraphPad Prism software. In all cases statistical significance was set at $\mathrm{p}<0.05$. In all the Figures, the bars indicate the standard error and statistical significance is indicated by asterisks.

\section{RESULTS AND DISCUSSION}

After polymerization of the copolymer network, extraction of the porogen template was performed by swelling in acetone which is a good solvent of the template. After extraction of the template, acetone was slowly changed by water. Then the sponge with the pores filled by water was dried. In this case, the copolymer network is strong enough to maintain the pore open since its ability for water sorption is quite limited due to the small content of hydroxyethyl acrylate and its state at room temperature is that of a hard rubber. With this procedure scaffold with completely open pore was produced (see Figure 1a).

The obtained scaffold was allowed to swell to equilibrium in acetone. In these conditions the copolymer at room temperature is much above its glass transition due to the plasticizing effect of the solvent, and thus it is very soft. If acetone is allowed to evaporate while the sample is at room ambient on a flat surface, solvent filling the pores evaporates faster than that swelling the polymer which must be desorbed from the polymer network. Thus the polymer network remains very soft during the first stages of drying. The result is that the pores collapse with an important 
decrease of thickness [41]. This effect is used in this work to produce thin macroporous membranes.

This collapse was produced from initial scaffolds of varying thickness while the final thickness of the membrane was always $100 \mu \mathrm{m}$ within a $10 \%$ error. Then, the degree of pore collapse and thus the porosity and pore connectivity of the membrane can be modulated. To achieve that, the original scaffold was cut to produce sheets of varying thickness that were allowed to swell to equilibrium in acetone and then allowed to dry at room conditions. When the membrane thickness reached $100 \mu \mathrm{m}$, membrane was suddenly immersed in water to stop contraction and thin membranes with different pore architecture are obtained (see Figure 1b-f). It is worth noting that thanks to the variation of the cross-linking density of the P(EA-co-HEA) copolymer network, i.e., the amount of EGDMA added in the polymerization, important material properties can be modulated. Thus, with increasing cross-linking density the glass transition temperature, $T_{g}$, and the elastic modulus increases while the acetone absorption capacity decreases. These properties determine the microstructure of the formed membrane.

\section{Microstructure or morphology of macroporous membranes}

The porosity of the PMMA template was $9 \pm 5 \%$ which should give to the scaffolds a theoretical porosity of $91 \pm 5 \%$. The final porosity was slightly smaller, showing a certain contraction of the scaffold during template extraction. Materials with higher crosslinking density should be closer to this value. Porosity of the departure scaffold before collapse was $(78 \pm 4) \%$ for COP-1-R, $(83 \pm 3) \%$ for COP-3-R and $(87 \pm 4) \%$ for COP-5-R. We can observe that when the cross-linking density was increased, the porosity also increased. Assuming that the contraction is produced mainly in the vertical direction, estimation based on geometric considerations yields that porosity decreases drastically with the contraction ratio $\mathrm{R}$. For $\mathrm{R}=1.8$ the porosity decrease to $50-70 \%$, for $\mathrm{R}=3$ the porosity falls below $50 \%$ and for $\mathrm{R}$ equal or greater to 5 the porosity is very close to zero, and as we will see below the membrane nearly become a rough film. 
To further analyze the microstructure at surface level of the macroporous membranes and to verify the porosity and interconnectivity after pore collapse, SEM micrographs of each type of macroporous membrane were taken, and compared with the structure previous to collapse. The pore diameters were measured from SEM images.

Figures 1 shows SEM images of macroporous membranes before (Figure 1a) and after pore collapse (Figure 1b-f). Figure 1a shows the appearance of the original isotropic scaffold with well interconnected spherical pores.
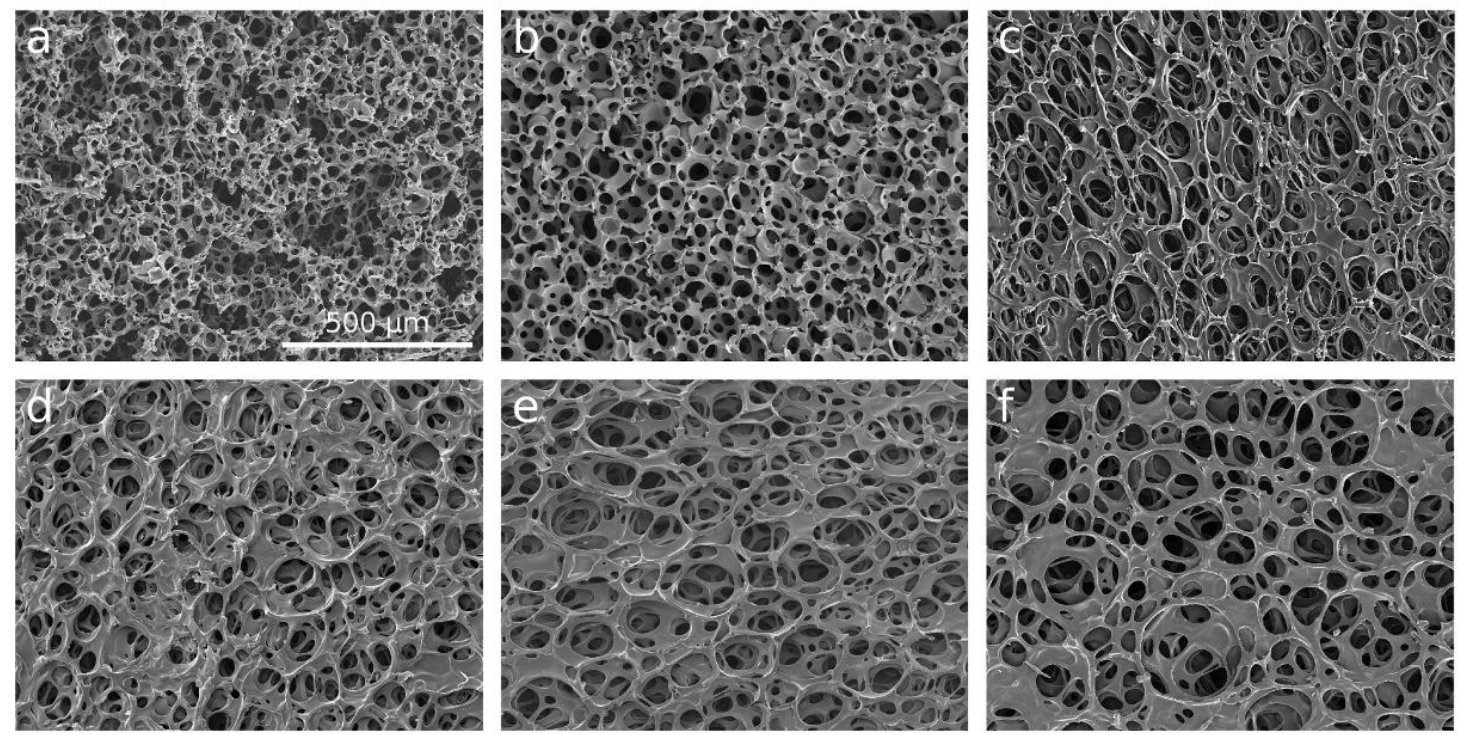

Figure 1. a) SEM micrographs of scaffold before collapse. SEM micrographs of $100 \mu \mathrm{m}$ thick porous membranes for COP-1-R series ( $1 \mathrm{wt} \%$ amount of cross-linking agent): b) $\mathrm{R}=1.8, \mathrm{c}$ ) $\mathrm{R}=5$ and d) $\mathrm{R}=15$. SEM micrographs of porous membranes for COP-X-R5 series (500 $\mu \mathrm{m}$ thicknesses before pore collapse) and different amount of cross linking agent: e) $3 \%$ and f) 5\%. All photographs have been taken at the same magnification.

The final pore architecture depends on the ratio of the initial thickness of the scaffold sheet to the final thickness after sample drying that was always 100 microns. From the micrographs of Figure 1b-d we may observe that with increasing the thickness before pore collapse there is a greater tendency to collapse and to loss widening pore circularity. Thus the sample obtained by the contraction of a scaffold $180 \mu \mathrm{m}$ thick, $\mathrm{R}=1.8$ (Figure $1 \mathrm{~b}$ ) is quite similar to the original one (Figure 1a), while in the other side that obtained from a sheet $1500 \mu \mathrm{m}$ thick, $\mathrm{R}=15$, (Figure 1d) 
the pores seem crushed. Furthermore, lower membrane porosity is distinguished when increasing thickness before pore collapse, which is visually appreciated by the proximity to the surface of the trabeculae observed inside of each pore appearing at the surface. It is worth noting that pores collapse is highly anisotropic. As shown in Figure 1 and table 1, the diameter of the pores observed are similar to that of the original scaffold, while in average in the dimension perpendicular to the surface they had to be reduced by the ratio $\mathrm{R}$.

\begin{tabular}{|l|c|c|c|}
\cline { 2 - 4 } \multicolumn{1}{c|}{} & \multicolumn{3}{c|}{ Amount of cross linking agent } \\
\hline Collapse ratio & COP-1 & COP-3 & COP-5 \\
\hline Scaffold before collapse & $37.9 \pm 7.1 \mu \mathrm{m}$ & $44.4 \pm 4.1 \mu \mathrm{m}$ & $42.4 \pm 4.6 \mu \mathrm{m}$ \\
\hline $\mathbf{R}=\mathbf{1 . 8}$ & $44.9 \pm 6.0 \mu \mathrm{m}$ & $55.7 \pm 4.9 \mu \mathrm{m}$ & $57.8 \pm 6.3 \mu \mathrm{m}$ \\
\hline $\mathbf{R}=\mathbf{3}$ & $56.4 \pm 7.7 \mu \mathrm{m}$ & $42.0 \pm 5.1 \mu \mathrm{m}$ & $52.3 \pm 5.6 \mu \mathrm{m}$ \\
\hline $\mathbf{R}=\mathbf{5}$ & $60.0 \pm 6.8 \mu \mathrm{m}$ & $61.1 \pm 6.9 \mu \mathrm{m}$ & $68.9 \pm 8.9 \mu \mathrm{m}$ \\
\hline $\mathbf{R}=\mathbf{1 5}$ & $32.8 \pm 4.1 \mu \mathrm{m}$ & $31.2 \pm 5.5 \mu \mathrm{m}$ & $33.1 \pm 8.1 \mu \mathrm{m}$ \\
\hline
\end{tabular}

Table 1: Pore diameter for the scaffold before collapse, and thin macroporous membranes for different amount of cross linking agent and collapse ratio. Results are expressed as mean value \pm standard deviation.

On the other hand, pore morphology depends on cross-linking density [21]. By increasing crosslinking density swelling capacity of the polymer network decreases $[47,48]$ and, as a consequence, volumetric changes in the scaffold trabeculae during swelling and deswelling are smaller. On the one hand, the pore structure of the original scaffold shows thinner trabeculae and more interconnected pores (results not shown) since the scaffold increases less its volume during the extraction of the PMMA template and on the other hand lower shrinkage of the pore structure takes place on pore collapse as it has been shown in a previous study [41] . The result, as shown in Figure 1c, 1e and 1f, is that on increasing cross-linking density, the membrane is more resistant and it swells less in acetone before collapse process, thus the pores of the collapsed membrane looks more open and interconnected, like the initial membrane.

These results are encouraging since they show the possibility of designing the pore architecture of the thin membrane and adjust it to optimize cell seeding and viability. 
Since SEM pictures do not provide a complete view of the interconnection and the degree of crushing of pores, to complete the analysis of the pore structure, 3D reconstruction geometry from confocal microscope has been used. 3D reconstruction allows getting a view of the pore depths and their interconnectivity. In the supplementary data section, an example of the obtained confocal images can be found. Confocal measurements probe that pores in samples with collapse ratio up to $\mathrm{R}=5$ continue to be interconnected and in some cases, the pores go from one face to another of the membranes, despite the fact that the pores suffer some crushing. In the case of collapse ratio $\mathrm{R}=15$, a film-like structure is observed, with a high rough surface topography, but without any pores able to allocate cells inside.

\section{$\underline{\text { Mechanical properties }}$}

Looking for the adequate balance between porosity and mechanical performance tensile and tearing experiments were carried out to obtain a correlation between processing and mechanical behavior of the thin membranes. In tearing experiments the force required to move the thread at a constant rate until breakage of the sample was measured. Tearing strength was defined as the maximum force in the crack propagation region. Note that the results obtained in the different samples can be compared with each other since the geometry of the samples, in particular sample thickness, is the same in all of them. All the samples, except COP-1-R1.8, present a tearing resistance above $0.1 \mathrm{~N}$ (see figure 2a) which it is significantly higher than the required resistance for surgical suture, around $0.04 \mathrm{~N}$, and very close to the value of $0.5 \mathrm{~N}$ where the sutures themselves broke [43]. 

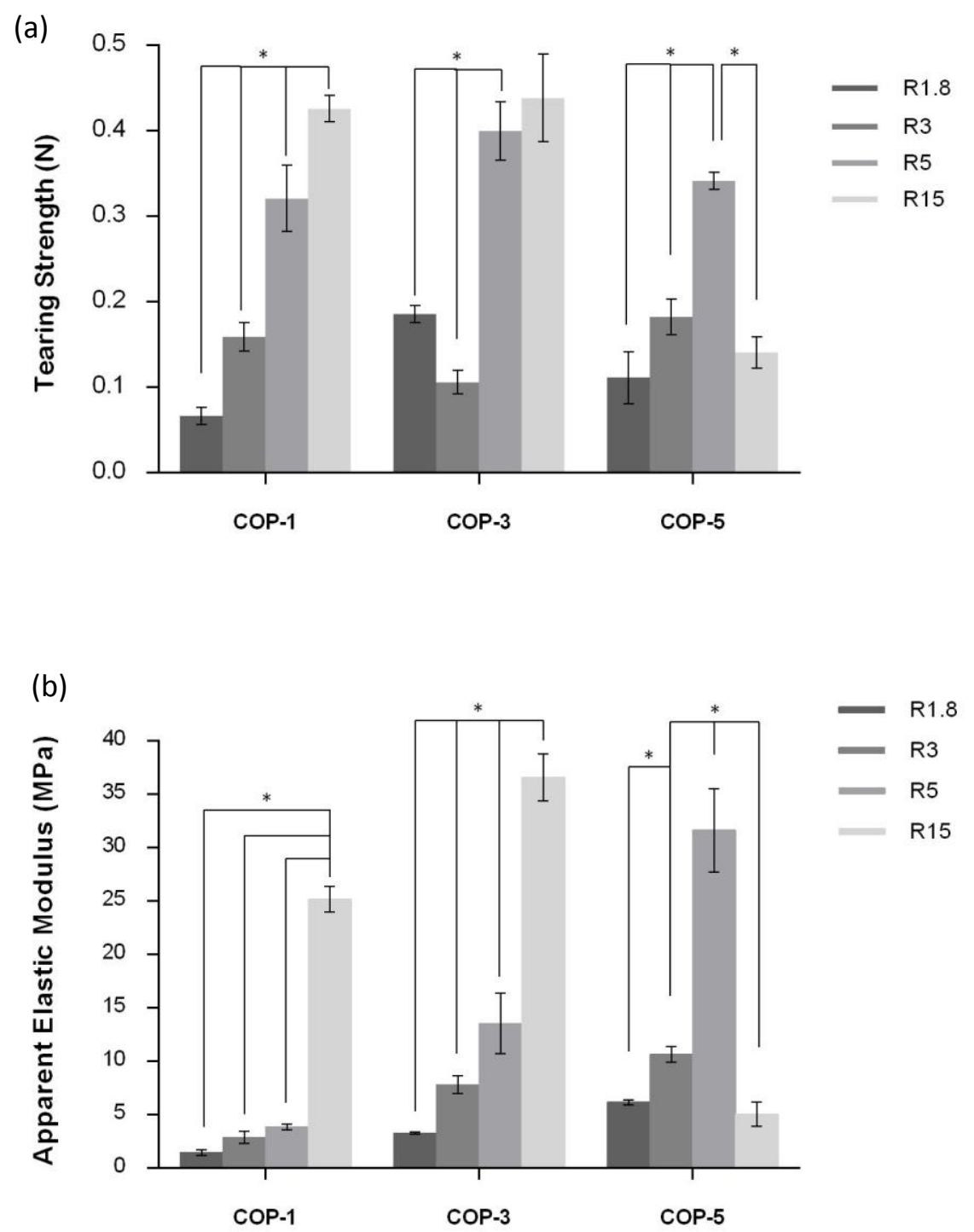

Figure 2. Results of mechanical assays: a) maximum tearing strength and b) apparent elastic modulus of the different macroporous membranes for $1 \mathrm{wt} \%, 3 \mathrm{wt} \%$ and $5 \mathrm{wt} \%$ content of cross-linking agent and $\mathrm{R}=1.8,3,5$ and 15 .

The other important characteristic of mechanical behavior of the membranes is its stiffness. Least squares fit of the linear deformation zone of stress-strain curve obtained in the tensile test experiment allowed calculating the apparent elastic modulus (Figure 2b).

The results show that both stiffness and tearing stress increase with increasing collapse ratio R. It seems that effective cross-section of the membrane is one of the crucial parameters controlling mechanical performance of the material. It is worth note that a non-collapsed $100 \mu \mathrm{m}$ thick membrane completely disintegrates since the thickness is approximately equal to the pore 
diameter, and pores in this membrane would be spherical. Interestingly enough, membranes with only $\mathrm{R}=1.8$ are mechanically consistent. Tearing resistance rapidly increases with collapse ratio in parallel to the decrease of porosity. Crack propagation is obviously favored by membrane porosity. Something similar can be said with respect to elastic modulus (Figure 2).

The other characteristic of the membrane determining mechanical performance is cross-linking density. Increasing the amount of cross-linking agent the mechanical resistance and the stiffness of the membrane trabeculae increase producing higher values of tearing strength and elastic modulus of the membrane. Sample COP-5-R15 is an exception showing a fragile fracture, and poor mechanical performance, it seems that so strong collapse in a highly cross-linked material produce an important number of defects in the structure that induces crack propagation and additional modes of deformation that makes the material more compliant than expected.

We may conclude that the optimum mechanical properties were obtained for an intermediate cross-linking density, $3 \mathrm{wt} \%$ EGDMA, regardless of the initial thickness. For this reason, short time culture studies has been done for all the materials, but long time culture studies has been done only for the material with $3 \mathrm{wt} \%$ EGDMA content.

\section{Cell seeding in macroporous membranes}

The study of biological response "in vitro" sought on the one hand to find the porosity requirements to allow cell seeding into the pores of these membranes and on the other hand to compare the capacity of expansion of bone marrow mesenchymal stem cells lodged into more or less flattened pores in a 3D scaffolding material or adhered on the membrane surface more similar to a monolayer. 

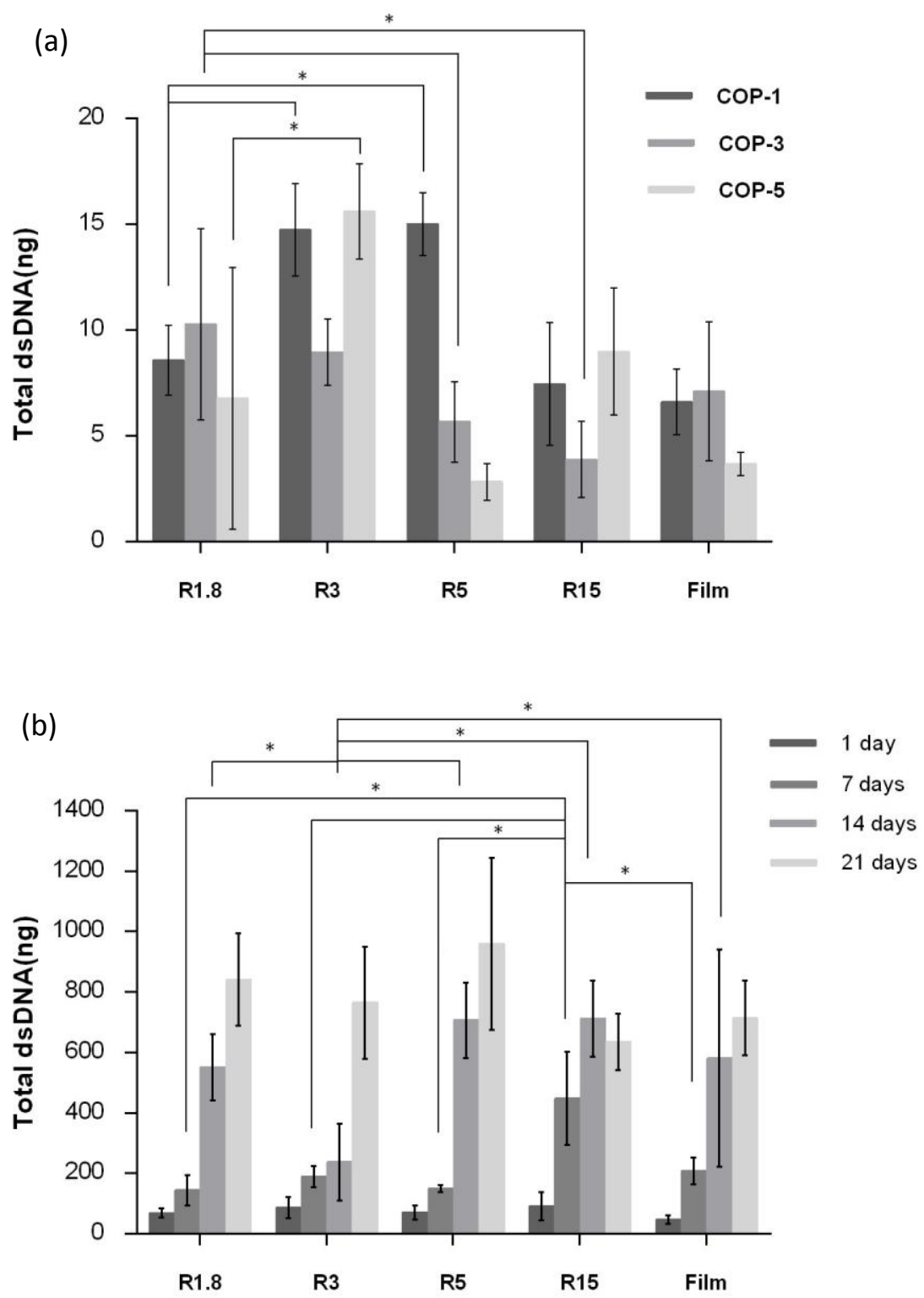

Figure 3. Total dsDNA quantification of the different macroporous membranes and film for: (a) $1 \mathrm{wt} \%$, $3 \mathrm{wt} \%$ and $5 \mathrm{wt} \%$ amount of cross-linking agent and $\mathrm{R}=1.8,3,5,15$ and film for 2 hours of culture and (b) 3 wt \% amount of cross-linking agent and $\mathrm{R}=1.8,3,5,15$ and film for 1, 7, 14 and 21 days of culture.

Seeding of cells into the samples was performed in all of them by placing the cell suspension on the surface of the membrane. Seeding efficiency was measured after 2 hours of culture, while proliferation until 21 days of culture was analyzed in independent experiments. The total amount of dsDNA at 2 hours is presented in Figure 3a for all macroporous membranes. Figure 
$3 \mathrm{~b}$ shows the results at $1,7,14$ and 21 days of culture for the sample cross-linked with $3 \mathrm{wt} \%$ EGDMA.

Tested samples showed a significant correlation between the cell seeding efficiency and collapse ratio. The samples with lower initial thickness showed the highest cell seeding regardless of the crosslink degree.

Figure 3 shows that the number of cells initially attached to the material is larger in the highly porous membranes $(\mathrm{R}=1.8$ or 3 ) than in the film or in the fully collapsed sample with $\mathrm{R}=15$. This means that in the less collapsed samples cells penetrate into the pores and probably there is a layer of cells attached to the surface as well as we will show below. On the contrary the fully collapsed samples present a continuous surface for cell attachment with superficial cavities but no accessible pores, thus quite similar to the film. The intermediate collapse ratio $\mathrm{R}=5$ shows a behavior that highly depends on cross-linking density. It seems that cell numbers decrease rapidly with increasing cross-linking density. It is worth note that this effect is not found in films or membranes with higher porosity and must be ascribed to the topography of the membranes. As shown in Figure 1e and 1f, the trabeculae in COP-5-R5 membrane are thinner than in COP-3-R5 and with higher curvature, these surfaces seem to me less effective for the initial cell attachment during cell seeding.

To further analyze cell attachment, vinculin distribution in the cells is presented in Figure 4a and actin cytoskeleton is shown in Figure 4b. It can be observed that most of the cells spread on the flat films already after two hours culture and present diffuse vinculin and actine distributed in the cytoplasm although neither focal adhesions nor actin stress fibers are still shown. The appearance of the cells on the membranes with $\mathrm{R}=15$ is similar to that of the film in agreement with the results of total DNA presented in Figure 3. In the porous membranes most of the cells present round morphology although they mark positive for diffuse vinculin and actin. Nevertheless some of the cells spread in these samples as well which corresponds to the larger heterogeneity in the topography of the surfaces to which can adhere inside the pores and at the external surface of the membrane. 


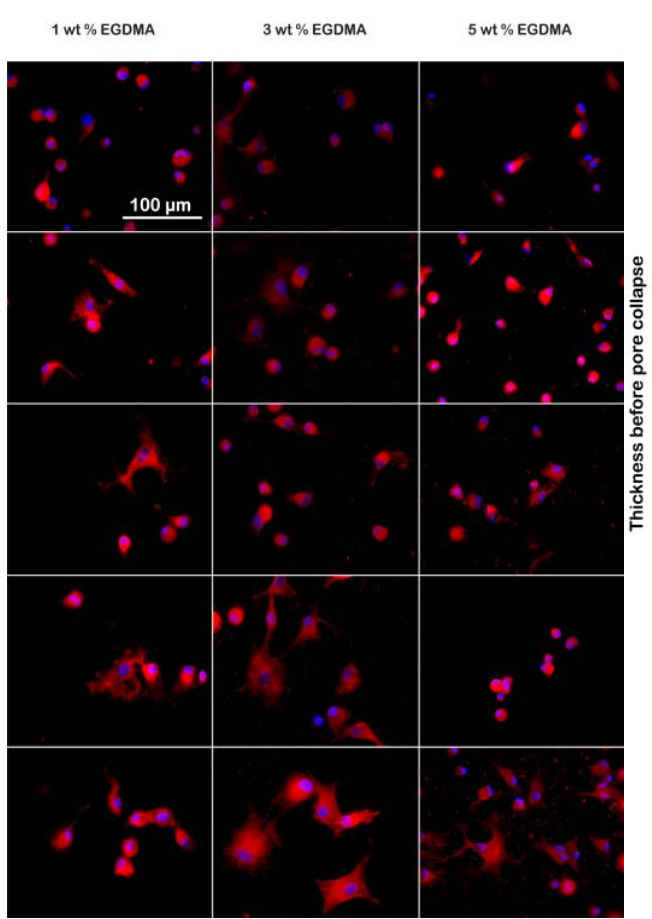

(a)

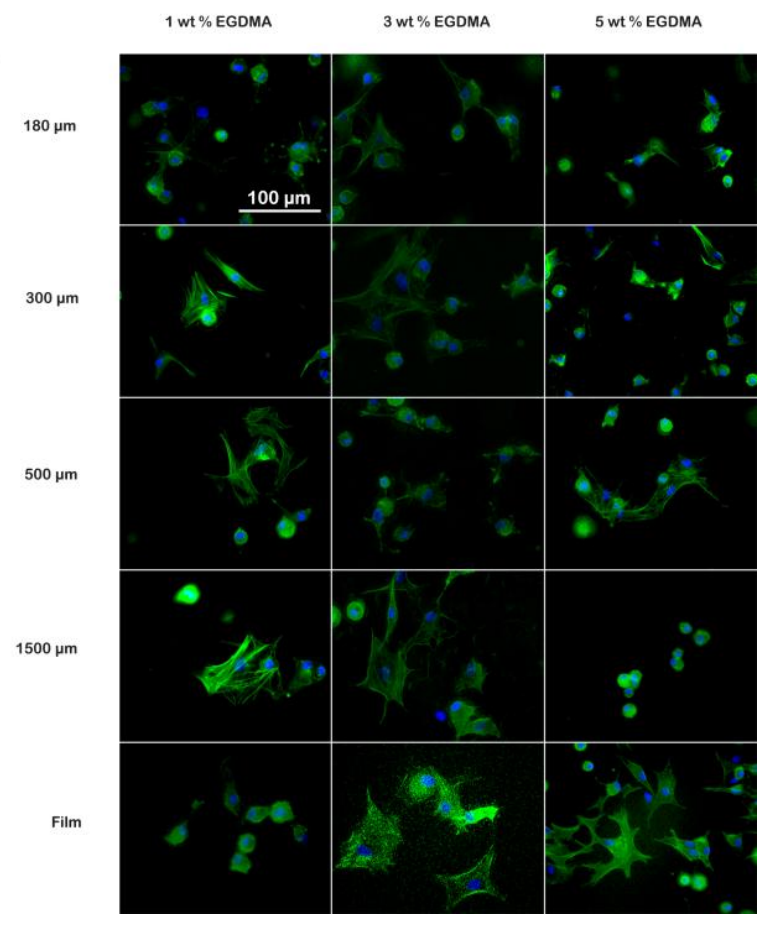

(b)

Figure 4. Immunofluorescence analysis of a) vinculin distribution and b) actin cytoskeleton at two hours culture for COP-X-R samples. Scale bar $110 \mu \mathrm{m}$. 


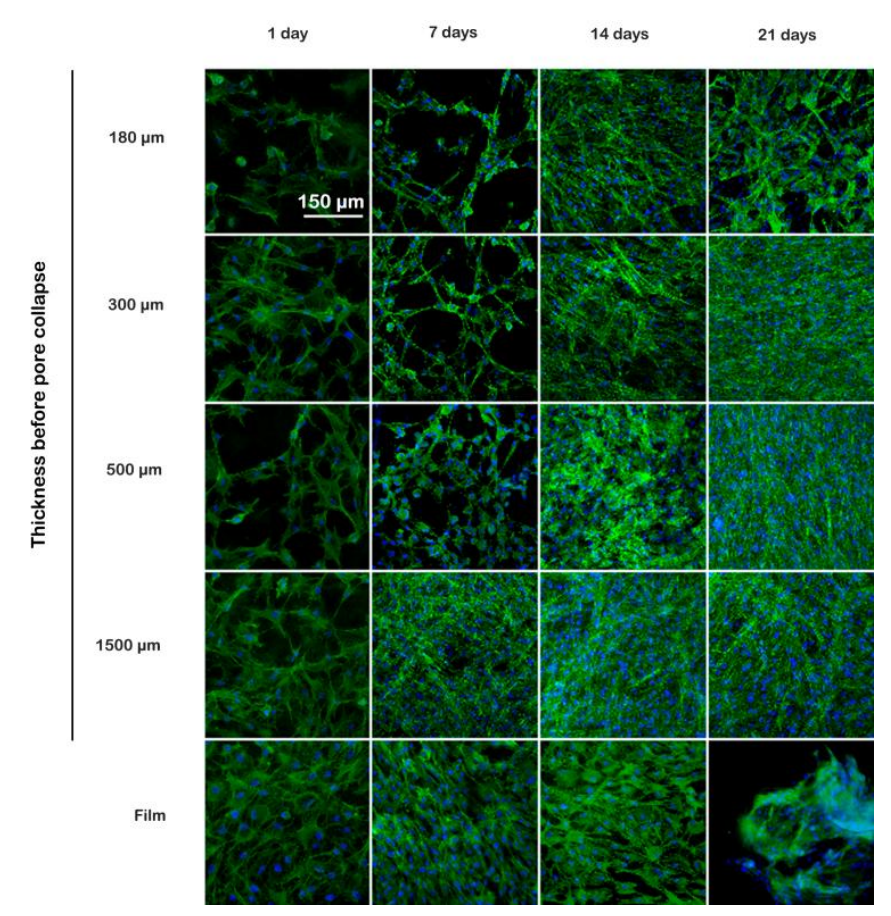

Figure 5. Confocal microscopy images of mesenchymal stem cells proliferation assay at 1, 7, 14 and 21 days of culture for non-porous film and macroporous membranes of different collapse ratio for COP-3 sample. Cells were stained with DAPI (blue) and phalloidin (green) to see the nucleus and cytoskeleton, respectively. Scale bar $150 \mu \mathrm{m}$.

The evolution of total DNA content with culture time shows that cells proliferated in all the samples. Nevertheless proliferation rate varies depending on the collapse ratio of the membranes. This feature is clearer in the pictures of fluorescence microscopy of Figure 5. Actin cytoskeleton was stained with phaloidin (green). At 1 day culture cells show extended morphology in all the samples and already at this short culture time, the number of cells in the film and the fully collapsed, $\mathrm{R}=15$, sample seems to be larger than in the porous membranes with $\mathrm{R}=1.8$ or 3 , in spite that as has been shown above seeding efficiency in the later was higher. According to the fluorescence images it seems that proliferation of the cells in monolayer is faster than inside the pores in a three-dimensional environment. Anyway cells raise confluence at 21 days of culture independently of their collapse ratio. 
In order to deeper analyze this feature and to conclude about the ability of the cells to proliferate inside the pores of the membrane, confocal microscopy was used. A stack of all the images taken every $1.5 \mu \mathrm{m}$ from the surface down to the last cell detected is analyzed. From these images it is possible to count the number of cells in layers at different depth in the membrane ( 0 for the surface, 15,30 and $40 \mu \mathrm{m}$ ) and thus to characterize the penetration of the cells in the pore structure and their proliferation ability as a function of the depth. Figure 6 shows that in the most porous sample $(\mathrm{R}=1.8)$ cells are evenly distributed in the membrane pores up to a depth of $40 \mu \mathrm{m}$ in the first day of culture. Nevertheless as culture time increases the number of cells at the surface continuously grows while in the deeper layers decreases. In is worth note that membranes are seeded on one side and the opposite side is open, thus nutrients can diffuse to the cells by both sides of the membrane and the decrease of the cells lodged in the deeper layers cannot be explained by the oxygen consumption of the cells situated closer to the surface. It seems that the result is due to a genuine lack of proliferation ability of the cells sited in a 3D environment with respect to those at the surface that behave like in a monolayer. The situation in the completely collapsed membranes $(\mathrm{R}=15)$ is just the opposite, initially, at day 1 of culture most of the cells are at the surface but some of them are able to find spaces in the pores close to the surface. However, surface cells rapidly proliferate and become confluent already at day 7 . For intermediate porosity $(\mathrm{R}=3$ or $\mathrm{R}=5$ ) the situation is between the extremes, cells at the surface become rapidly confluent but some cells reside in the pores close to the surface. 

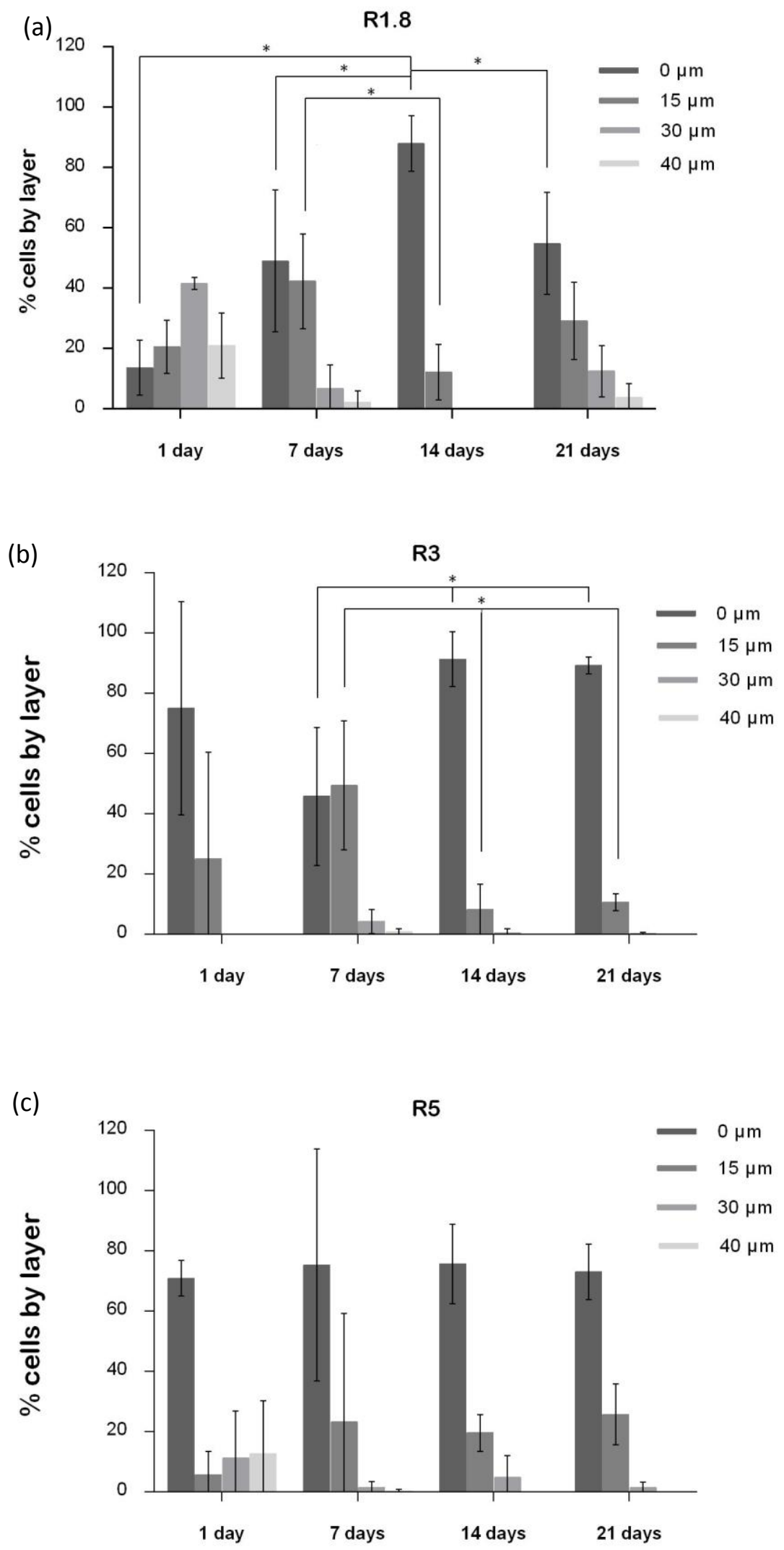
(d)

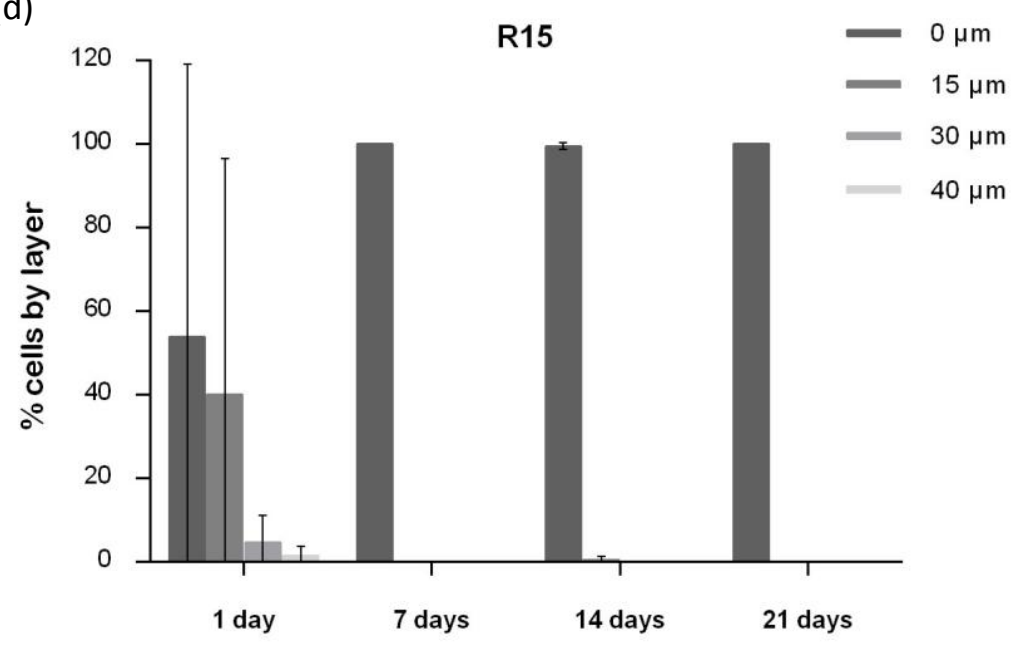

Figure 6. Tridimensional cell distribution and quantification for a) COP-3-R1.8, b) COP-3-R3, c) COP-3R5 and COP-3-R15 samples.

The results allow concluding that porosity of thin membranes can be modulated by anisotropic collapse of the pores starting from a scaffold with a structure of well interconnected spherical pores. In highly porous membranes it is possible to seed cells just leaving a drop of the cell suspension on the surface of the sample and cells penetrate up to a depth of $40 \mu \mathrm{m}$. Note that seeding on both surfaces cells would be distributed nearly in the total volume of the membrane. Mesenchymal stem cells cultured in basal medium do not proliferate inside the pores while they grow rapidly at the surface producing a layer of confluent cells. It is worth note that although these highly porous samples are mechanically weak their tearing resistance is high enough to allow suture. If larger stiffness or tearing resistance is required, less collapsed membranes can be produced, the improvement of the mechanical properties has its counterpart in the decrease of porosity and thus cell seeding possibilities. Anyway, intermediate collapse ratios allow obtaining flexible, easy to handle, resistant membranes that can host MSCs in their pores. Cross-linking density of the polymer network is another important parameter in the design of the membranes, it controls not only the stiffness of the resulting material but also the anisotropic collapse process since solvent absorption in the polymer network rapidly decreases with crosslinking density and the amount of solvent absorbed by the polymer influences the 
contraction ability of the macroporous scaffold during solvent evaporation. Thus for the same collapse ratio R, more open pores and thinner trabeculae are obtained when crosslinking density increases.

\section{CONCLUSION}

The obtained results prove that the proposed method has great versatility in producing membranes with varying properties: low original thickness to final thickness ratio and high crosslinking density produce highly porous membranes favoring cell or tissue invasion while high original thickness to final thickness ratio and low cross-linking density produce membranes with better mechanical properties.

Obtained membranes are porous enough with suitable pore size to hold cells to be transplanted to the organism and they present sufficient tearing stress to be sutured with surgical thread. Mesenchymal stem cells lodged close to the membrane surface proliferate when cultured in basal medium while proliferation is nearly suppressed in deeper pore layers.

\section{ACKNOWLEDGMENTS}

This work was funded by the Spanish Ministry of Economy and Competitiveness (MINECO) through the project MAT2013-46467-C4-1-R (including the FEDER financial support). J.R.R. acknowledges funding of his $\mathrm{PhD}$ by the Generalitat Valenciana through VALipd grant (ACIF/2010/238). CIBER-BBN is an initiative funded by the VI National R\&D\&i Plan 2008e2011, Iniciativa Ingenio 2010, Consolider Program, CIBER Actions and financed by the Instituto de Salud Carlos III with assistance from the European Regional Development Fund. The authors acknowledge too the advice of Dr. Daniel Kelly, Dr. Conor Buckley and Dr. Yurong Liu about the isolation and expansion of porcine MSCs. The authors acknowledge the assistance and advice of Electron Microscopy Service of the UPV. 


\section{REFERENCES}

1. Sun, W., et al., Computer-aided tissue engineering: overview, scope and challenges. Biotechnology and Applied Biochemistry, 2004. 39: p. 29-47.

2. Hollick, E.J., et al., Legeais BioKpro III keratoprosthesis implantation: long term results in seven patients. Br J Ophthalmol, 2006. 90(9): p. 1146-51.

3. Hoffart, L., G. Carles, and F. Matonti, Lamellar corneal lenticule graft to treat keratolysis after AlphaCor keratoprosthesis implantation. Eur J Ophthalmol, 2014: p. 0.

4. Siegwart, D.J., J.K. Oh, and K. Matyjaszewski, ATRP in the design of functional materials for biomedical applications. Progress in Polymer Science, 2012. 37(1): p. 1837.

5. Sokolsky-Papkov, M., et al., Polymer carriers for drug delivery in tissue engineering. Advanced Drug Delivery Reviews, 2007. 59(4-5): p. 187-206.

6. Bakhshandeh, H., et al., Poly (epsilon-caprolactone) nanofibrous ring surrounding a polyvinyl alcohol hydrogel for the development of a biocompatible two-part artificial cornea. Int J Nanomedicine, 2011. 6: p. 1509-15.

7. Chirila, T.V., et al., Interpenetrating polymer network (IPN) as a permanent joint between the elements of a new type of artificial cornea. J Biomed Mater Res, 1994. 28(6): p. 745-53.

8. Myung, D., et al., Bioactive interpenetrating polymer network hydrogels that support corneal epithelial wound healing. J Biomed Mater Res A, 2009. 90(1): p. 70-81.

9. Levesque, S.G., R.M. Lim, and M.S. Shoichet, Macroporous interconnected dextran scaffolds of controlled porosity for tissue-engineering applications. Biomaterials, 2005. 26(35): p. 7436-7446.

10. Duan, H.C., et al., Engineering of epidermis skin grafts using electrospun nanofibrous gelatin/polycaprolactone membranes. International Journal of Nanomedicine, 2013. 8: p. 2077-2084. 
11. Walker, N.G., et al., A Chemically Defined Carrier for the Delivery of Human Mesenchymal Stem/Stromal Cells to Skin Wounds. Tissue Engineering Part C-Methods, 2012. 18(2): p. 143-155.

12. Pianigiani, E., et al., Human De-epidermized Dermis as a Stem Cell Carrier. Transplantation Proceedings, 2010. 42(6): p. 2244-2246.

13. Waaijman, T., et al., Use of a Collagen-Elastin Matrix as Transport Carrier System to Transfer Proliferating Epidermal Cells to Human Dermis In Vitro. Cell Transplantation, 2010. 19(10): p. 1339-1348.

14. Pal, K., A.K. Banthia, and D.K. Majumdar, Polymeric Hydrogels: Characterization and Biomedical Applications. Designed Monomers and Polymers, 2009. 12(3): p. 197-220.

15. Niu, G.G., et al., Heparin-modified gelatin scaffolds for human corneal endothelial cell transplantation. Biomaterials, 2014. 35(13): p. 4005-4014.

16. de la Mata, A., et al., Chitosan-gelatin biopolymers as carrier substrata for limbal epithelial stem cells. Journal of Materials Science-Materials in Medicine, 2013. 24(12): p. 2819-2829.

17. Levis, H.J., et al., Plastic Compressed Collagen as a Novel Carrier for Expanded Human Corneal Endothelial Cells for Transplantation. Plos One, 2012. 7(11): p. 10.

18. Hollister, S.J., Porous scaffold design for tissue engineering. Nature Materials, 2005. 4(7): p. $518-524$.

19. Dinu, M.V., et al., Morphogical and swelling properties of porous hydrogels based on poly(hydroxyethyl methacrylate) and chitosan modulated by ice-templating process and porogen leaching. Journal of Polymer Research, 2013. 20(11): p. 10.

20. Diego, R.B., et al., Acrylic scaffolds with interconnected spherical pores and controlled hydrophilicity for tissue engineering. Journal of Materials Science, 2005. 40(18): p. $4881-4887$.

21. Diego, R.B., et al., Acrylic scaffolds with interconnected spherical pores and controlled hydrophilicity for tissue engineering. Journal of Materials Science-Materials in Medicine, 2005. 16(8): p. 693-698. 
22. Huang, D., et al., Facile fabrication of gradient bioactive coating with hierarchically porous structures and superior cell response. Materials Letters, 2014. 133: p. 105-108.

23. Santamaria, V.A., et al., Influence of the macro and micro-porous structure on the mechanical behavior of poly(L-lactic acid) scaffolds. Journal of Non-Crystalline Solids, 2012. 358(23): p. 3141-3149.

24. Cruz, D.M.G., et al., Differentiation of mesenchymal stem cells in chitosan scaffolds with double micro and macroporosity. Journal of Biomedical Materials Research Part A, 2010. 95A(4): p. 1182-1193.

25. Lebourg, M., et al., Biodegradable polycaprolactone scaffold with controlled porosity obtained by modified particle-leaching technique. Journal of Materials ScienceMaterials in Medicine, 2008. 19(5): p. 2047-2053.

26. Siddiqui, N. and K. Pramanik, Effects of Micro and Nano beta-TCP Fillers in FreezeGelled Chitosan Scaffolds for Bone Tissue Engineering. Journal of Applied Polymer Science, 2014. 131(21): p. 10.

27. Deplaine, H., et al., Evolution of the Properties of a Poly(L-lactic acid) Scaffold with Double Porosity During In Vitro Degradation in a Phosphate-Buffered Saline Solution. Journal of Applied Polymer Science, 2014. 131(20): p. 10.

28. Demirdogen, B., et al., Silica coating of the pore walls of a microporous polycaprolactone membrane to be used in bone tissue engineering. Journal of Biomedical Materials Research Part A, 2014. 102(9): p. 3229-3236.

29. Bonilla, C.E.P., et al., New porous polycaprolactone-silica composites for bone regeneration. Materials Science \& Engineering C-Materials for Biological Applications, 2014. 40: p. 418-426.

30. Gaona, L.A., et al., Hydrolytic degradation of PLLA/PCL microporous membranes prepared by freeze extraction. Polymer Degradation and Stability, 2012. 97(9): p. 16211632. 
31. Lebourg, M., J.S. Anton, and J.L.G. Ribelles, Porous membranes of PLLA-PCL blend for tissue engineering applications. European Polymer Journal, 2008. 44(7): p. 22072218 .

32. Ho, M.H., et al., Preparation of porous scaffolds by using freeze-extraction and freezegelation methods. Biomaterials, 2004. 25(1): p. 129-138.

33. Silva, C.S.R., et al., Poly(e-caprolactone) Electrospun Scaffolds Filled with Nanoparticles. Production and Optimization According to Taguchi's Methodology. Journal of Macromolecular Science Part B-Physics, 2014. 53(5): p. 781-799.

34. Gomez-Tejedor, J.A., et al., Assessment of the parameters influencing the fiber characteristics of electrospun poly(ethyl methacrylate) membranes. European Polymer Journal, 2011. 47(2): p. 119-129.

35. Areias, A.C., et al., Assessment of parameters influencing fiber characteristics of chitosan nanofiber membrane to optimize fiber mat production. Polymer Engineering and Science, 2012. 52(6): p. 1293-1300.

36. Xiang, P., et al., A novel Bruch's membrane-mimetic electrospun substrate scaffold for human retinal pigment epithelium cells. Biomaterials, 2014. 35(37): p. 9777-88.

37. Wang, B.Y., et al., Electrospun polylactide/poly(ethylene glycol) hybrid fibrous scaffolds for tissue engineering. Journal of Biomedical Materials Research Part A, 2012. 100A(2): p. 441-449.

38. Martinez-Ramos, C., et al., Differentiation of postnatal neural stem cells into glia and functional neurons on laminin-coated polymeric substrates. Tissue Engineering Part A, 2008. 14(8): p. 1365-1375.

39. Soria, J.M., et al., Influence of the substrate's hydrophilicity on the in vitro Schwann cells viability. Journal of Biomedical Materials Research Part A, 2007. 83A(2): p. 463470.

40. Myung, D., et al., Design and fabrication of an artificial cornea based on a photolithographically patterned hydrogel construct. Biomedical Microdevices, 2007. 9(6): p. 911-922. 
41. Diego, R.B., J.L.G. Ribelles, and M.S. Sánchez, Pore collapse during the fabrication process of rubber-like polymer scaffolds. Journal of Applied Polymer Science, 2007. 104(3): p. 1475-1481.

42. Chang, H.-H., et al., Preparation of microporous poly(VDF-co-HFP) membranes by template-leaching method. Separation and Purification Technology, 2010. 72(2): p. 156-166.

43. $\mathrm{Li}, \mathrm{F}$., et al., Recruitment of multiple cell lines by collagen-synthetic copolymer matrices in corneal regeneration. Biomaterials, 2005. 26(16): p. 3093-3104.

44. ANSI/AAMI, Cardiovascular Implants-Vascular Prosthesis, Section 8.8 (Suture Retention Strength), in VP20:20-21, A.N.I.a.A.f.t.A.o.M. Instrumentation, Editor. 1994.

45. Gamboa-Martinez, T.C., et al., Chondrocytes Cultured in an Adhesive Macroporous Scaffold Subjected to Stirred Flow Bioreactor Behave Like in Static Culture. Journal of Biomaterials and Tissue Engineering, 2013. 3(3): p. 312-319.

46. Rodenas-Rochina, J., J. Ribelles, and M. Lebourg, Comparative study of PCL-HAp and PCL-bioglass composite scaffolds for bone tissue engineering. Journal of Materials Science-Materials in Medicine, 2013. 24(5): p. 1293-1308.

47. Flory, P.J. and J. Rehner, Statistical mechanics of cross-linked polymer networks II Swelling. Journal of Chemical Physics, 1943. 11(11): p. 521-526.

48. Kim, J.H., et al., Properties and swelling characteristics of cross-linked poly(vinyl alcohol) chitosan blend membrane. Journal of Applied Polymer Science, 1992. 45(10): p. $1711-1717$. 


\section{SUPLEMENTARY FIGURES}

In this section, we have included some figures, that for reason of space and clarity of the paper, we have considered more appropriate to locate here. These figures provide additional information to the main ideas described in the paper.

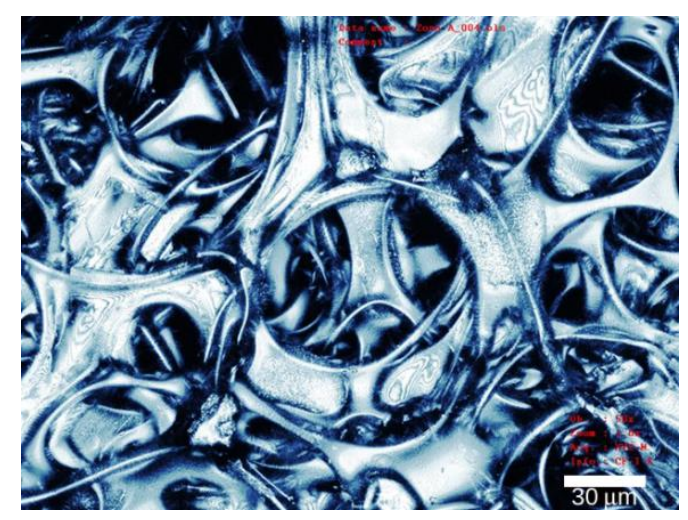

(a)

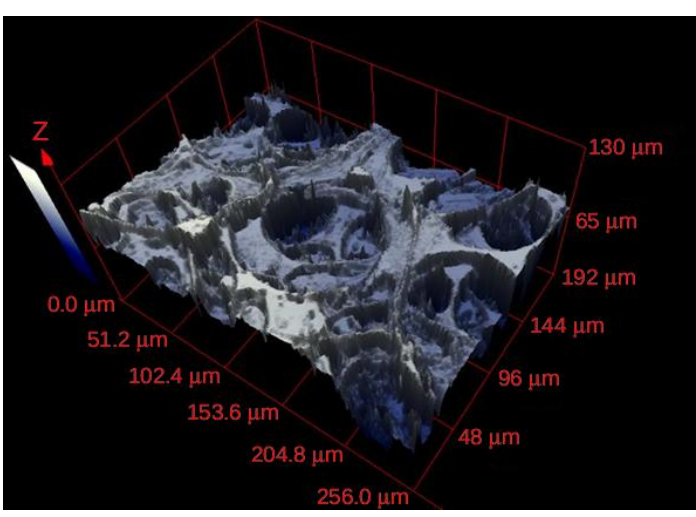

(b)

Figure S1. Confocal micrographs of $100 \mu \mathrm{m}$ thick porous membrane for COP-3-R5 sample (5wt \% amount of cross-linking agent and $500 \mu \mathrm{m}$ of initial thickness). (a) Image of the sample surface. (b) Three dimensional representation of the sample. We can appreciate that although the porosity has decreased, as it was expected, there are still pores large enough to host cells inside, and with a high degree of interconnection between them. 


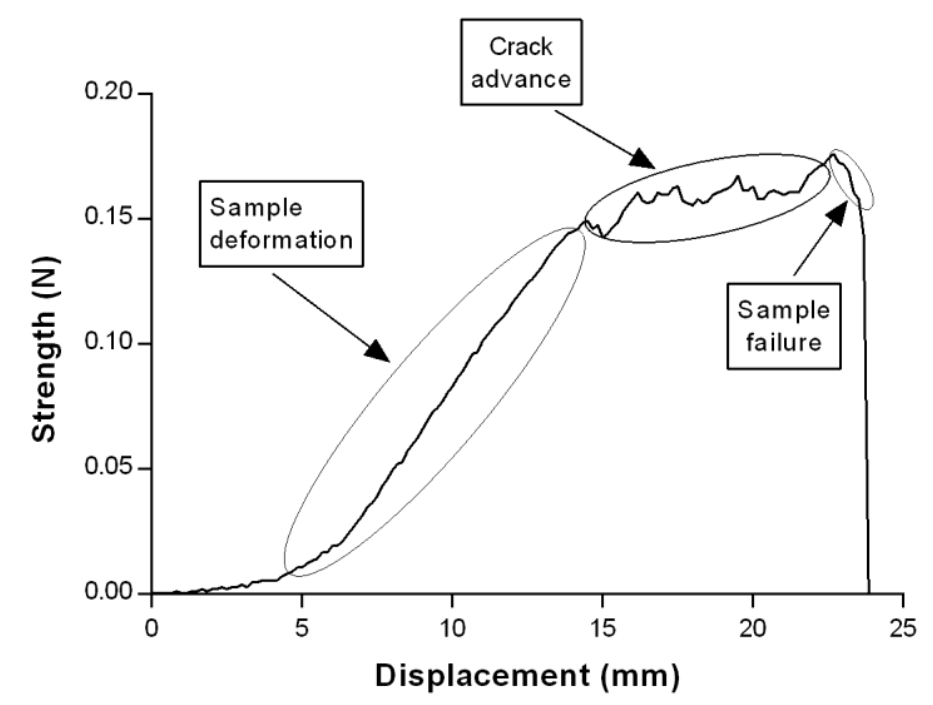

Figure S2. Results of tearing assay: measurement of the necessary strength to move the thread at a constant rate of $10 \mathrm{~mm} / \mathrm{min}$ for COP-1-R3 porous membrane. Three different zones can be distinguished in the force - displacement plot: sample deformation in the linear zone (before the start of the crack advance), crack propagation at nearly constant force and sample failure respectively.

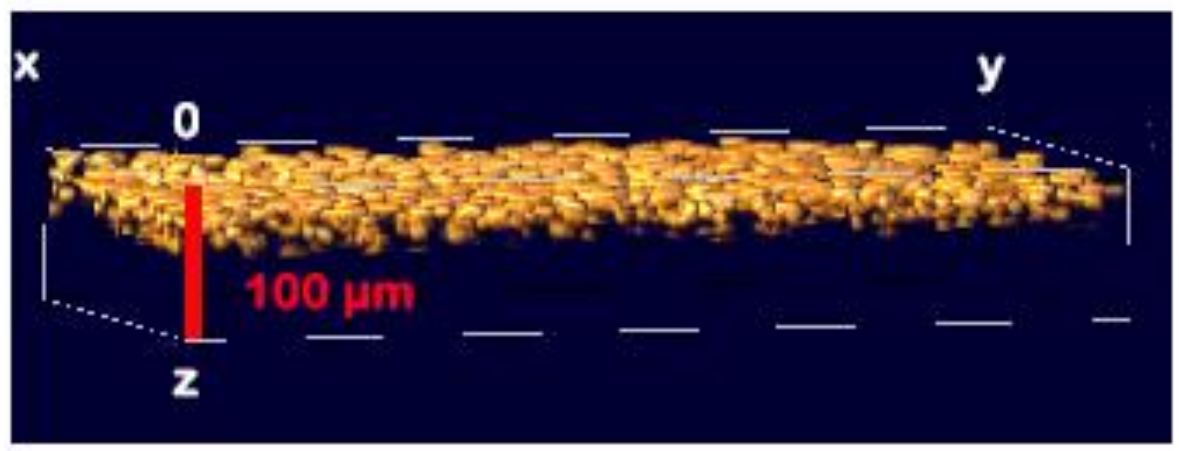

Figure S3. 3D representation of the penetration of the cells in the pore structure for COP-3-R1.8 sample after 21 days culture. 